Coptocycla catenata Boh. Wenn man auch nur wenige Stücke dieser Art vor sich hat, so begreift man nicht, wie Boheman, Cass. 4, 633, dazu gekommen ist, eine besondere Art, Westringi Boh., abzutrennen. Selbstverständlich vergleicht er letztere nicht etwa mit catenata, von der sie nicht verschieden ist, sondern mit punctaria, die allerdings ein wenig anders aussieht.

Die hellsten Stücke der catenata besitzen ein fast einfarbig gelbes Halssch., und sind dann der strigula Montr. ähnlich, die von den Philippinen bis zu den Aru-Inseln verbreitet ist. Nur zeigen sich vor dem Schildchen zwei schwarze Längsstriche, die bis zur Mitte der Scheibe (das Dach nicht mitgerechnet) reichen, in seltenen Fällen gänzlich durch eine feine, helle Linie getrennt sind und vorn etwas nach aufsen biegen. Sie fliefsen allmählich zu einem Längsstreifen zusammen, der vorn in zwei divergirende Spitzen endet; hierauf zeigt sich in der Nähe jeder Spitze ein schwarzer Punkt. Derselbe bildet sich zu einem bogenförmigen Striche aus, welcher sich einerseits mit der Spitze des Mittelstreifens verbindet, andrerseits zur Basis des Halssch. verlängert und hier meist makelförmig verbreitert. Die Zahl, Form und Anordnung der gelben, im Leben prächtig metallgrünen Reliefmakeln auf den Fld. variirt in überraschender Art.

J. W ei se.

\title{
Pachygnatha, eine neue Chrysomelen-Gattung.
}

Orina dolens Kraatz, Deutsche Ent. Zeitschr. 1885, 298, eine auffällige, ungeflügelte Chrysomele von Samarkand und Namagan, kommt nördlich bis Taschkent vor, wo sie von Leder gesammelt wurde. Ihr eigenthümlicher Körperbau wird durch den breiten, aber kurzen Kopf und das breite, grofse Halssch. bedingt, welches nach hinten nicht ganz so stark verschmälert, als bei Crosita, und an den Seiten weniger wulstartig verdickt ist. Sie unterscheidet sich aufserdem von den übrigen Chrysomelen durch die ungemein kurze, in der Mitte tief ausgebuchtete Oberlippe und die grofsen vortretenden Mandibeln mit weniger stumpfen und breiten Endzähnen.

Für dieses Thier errichte ich eine Gattung, die zwischen Crosita Motsch. und Chrysomela zu stellen ist: Pachygnatha. Corpus apterum, sat elongatum, convexiusculum, lateribus fere parallelis. Caput latum, breviusculum, fronte canaliculata; labrum brevissimum profunde emarginatum, mandibulae magnae. Prothorax magnus apice minus profunde emarginato quam basi parum angustior, lateribus sat rotundatis, callo laterali minus incrassato, depressione fortiter punctala terminato. Elytra seriatim punctata. J. Weise. 


\section{$2 \mathrm{BHL}$ Biodiversity Heritage Library}

Weise, Julius. 1892. "Pachygnatha, eine neue Chrysomelen-Gattung." Deutsche entomologische Zeitschrift 1892(1), 352-352.

https://doi.org/10.1002/mmnd.48018920116.

View This Item Online: https://www.biodiversitylibrary.org/item/103434

DOI: https://doi.org/10.1002/mmnd.48018920116

Permalink: https://www.biodiversitylibrary.org/partpdf/235530

\section{Holding Institution}

Harvard University, Museum of Comparative Zoology, Ernst Mayr Library

\section{Sponsored by}

Harvard University, Museum of Comparative Zoology, Ernst Mayr Library

\section{Copyright \& Reuse}

Copyright Status: Public domain. The BHL considers that this work is no longer under copyright protection.

This document was created from content at the Biodiversity Heritage Library, the world's largest open access digital library for biodiversity literature and archives. Visit BHL at https://www.biodiversitylibrary.org. 